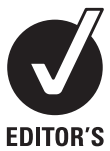

CHOICE

\title{
More effective home heating reduces school absences for children with asthma
}

\author{
S Free, P Howden-Chapman, N Pierse, H Viggers, the Housing, Heating and Health \\ Study Research Team*
}

Housing and Health Research Programme, University of Otago, Wellington, Wellington South, New Zealand

\section{Correspondence to} Professor Philippa

Howden-Chapman, He Kainga Oranga/Housing and Health Research Programme, University of Otago, Wellington, PO Box 7343, Wellington South 6242, New Zealand; philippa-howden-chapman@ otago.ac.nz

For author footnote see end of the article.

Accepted 2 July 2009

\section{ABSTRACT}

Background New Zealand homes are underheated by international standards, with average indoor temperatures below the WHO recommended minimum of $18^{\circ} \mathrm{C}$. Research has highlighted the connection between low indoor temperatures and adverse health outcomes, including social functioning and psychological well-being. Both health effects and social effects can impact on school absence rates. The aim of this study was to determine whether more effective home heating affects school absence for children with asthma.

Methods A single-blinded randomised controlled trial of heating intervention in 409 households containing an asthmatic child aged $6-12$ years, where the previous heating was an open fire, plug-in electric heater or unflued gas heater. The intervention was the installation of a more effective heater of at least $6 \mathrm{~kW}$ before the winter of 2006 in half the houses. Demographic and health information was collected both before and after the intervention. Each child's school was contacted directly and term-by-term absence information for that child obtained for 2006 and previous years where available.

Results Complete absence data were obtained for 269 out of 409 children. Compared with the control group, children in households receiving the intervention experienced on average $21 \%(p=0.02)$ fewer days of absence after allowing for the effects of other factors. Conclusion More effective, non-indoor polluting heating reduces school absence for asthmatic children.

Educational attainment is both a consequence and a cause of good health, as people with more education are more likely to be in better health and to live longer. ${ }^{1}$ School attendance is one of the pathways to educational attainment, but although there is an understanding of the impact of different educational systems, there is little research on family influences on school attendance and even less on the impact of the built environment.

As children with a chronic illness, such as asthma, are likely to have significantly more days off school than healthy children, it is important to try to minimise the occurrence and severity of their asthma symptoms to prevent adverse impacts on their education and thus their lifetime health. The model developed by Mackenbach to reduce inequalities in health has been adopted as a framework for health policy to reduce health inequalities in New Zealand and highlights that one critical strategy is intervening to reduce the effects of chronic illness. ${ }^{2}$

\section{ASTHMA AND SCHOOL ATTENDANCE}

There are many studies that indicate that asthma contributes to absence from school. A 2005 literature review of 66 studies addressing asthma and school attendance found that virtually all studies showed a connection between asthma and reduced school attendance. ${ }^{3}$ However, limitations in study design, including the lack of a control group in many cases and the lack of a standard definition of "asthma" and its severity, have meant that that it is difficult to quantify the number of school days lost as a result of the disease. A 2004 US study on the economic cost of asthma estimated the additional absence to be as high as 2.8 days per asthmatic child per year, ${ }^{4}$ whereas a 2002 study by Moonie et al indicates a figure of approximately $1.3-1.5$ days per child per year. However, other recent studies have found no effect. ${ }^{7}$ Research shows that the situation is complex, with absence potentially affected by a wide range of variables including the severity of asthma symptoms, ${ }^{5} 8$ the degree of compliance with medication regimens, ${ }^{9}$ social deprivation and low socioeconomic status ${ }^{10}{ }^{11}$ and parenting styles. ${ }^{10}$

\section{THE INDOOR ENVIRONMENT AND ASTHMA}

Figure 1 outlines some of the ways in which factors in the child's home and school environment may potentially combine with personal health and motivational factors to influence school attendance. This study investigates the possibility that heating choice and availability of heating may have an impact on school attendance through the effects on respiratory illness and asthma.

Although the mechanisms are poorly understood and under-researched, the quality of the home environment may have a large impact on health This is of some importance because, in Western societies, people may spend up to $90 \%$ of their time indoors. ${ }^{12}$ Richardson et al ${ }^{13}$ in their 2005 literature review concluded that there is evidence of a link between the indoor environment and asthma. Ventilation, and improved insulation and heating are associated with reduced indoor humidity, which in turn reduces levels of moulds and dust mites, as dust mites cannot survive when relative humidity levels are less than approximately $50 \%{ }^{14}$ Both mould spores ${ }^{15-19}$ and dust mite allergen ${ }^{20} 21$ have been associated with asthma and respiratory symptoms.

One UK study, which involved installing central heating into 59 cold and damp homes in Cornwall, England, ${ }^{22}$ showed that after the intervention, there was a statistically significant reduction in 
Figure 1 The impact of home heating and other factors on school attendance.
THE IMPACT OF HOME HEATING ON SCHOOL ATTENDANCE

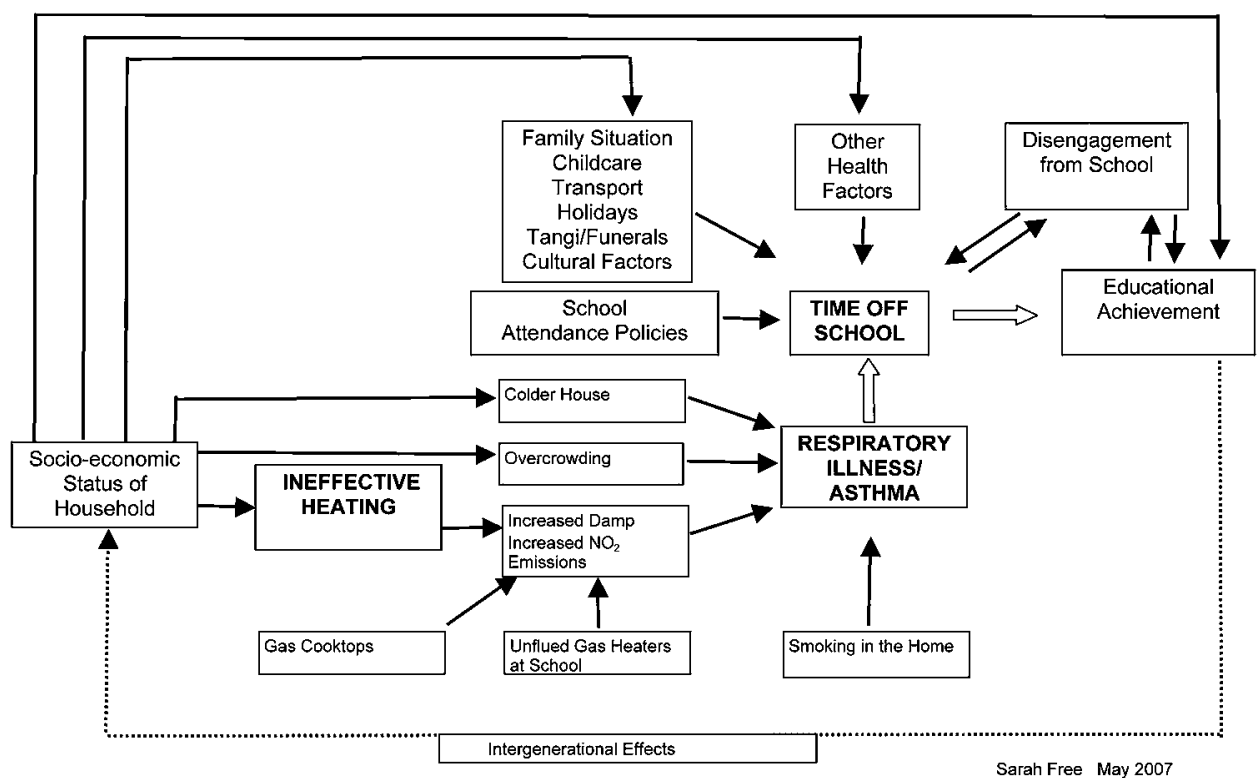

measured respiratory symptoms for the 72 asthmatic children participating in the study. This was particularly evident for selfreported night coughing, which was reduced from a score of 3 (most nights) to 1 (one or several nights) measured over a month $(p<0.001)$. Night coughing has previously been found to be associated with loss of sleep and subsequent absence from school. ${ }^{23}$ In the Cornwall study, self-reported school absences for asthma were significantly reduced to 2.1 days per 100 compared with 9.3 days per 100 before the intervention $(p<0.01)$. The results are interesting; however, the lack of a control group and the use of self-reported data meant that effects of seasonality, age and recall bias could not be accounted for.

\section{LOW INDOOR TEMPERATURES AND HEALTH}

New Zealand homes tend to be poorly insulated and are cold by international standards. ${ }^{24}{ }^{25}$ Only $5 \%$ of New Zealand homes have central heating, ${ }^{26}$ and up to $2 \%$ of New Zealand homes use no heating at all.

Low temperatures in New Zealand homes may contribute to the excess winter mortality that is evident in both young children $<5$ years old and older people $>80$ years old in New Zealand. ${ }^{27}$ For New Zealand children $<5$ years old, mortality associated with respiratory disease was estimated to be almost 2.5 times higher in winter than expected. ${ }^{27}$

Excess winter morbidity is harder to measure than mortality, but there is evidence that it follows a similar pattern. New Zealand hospitalisation data show an excess of hospital admissions in winter for the older people and children $<5$ years old. ${ }^{28}$ There is also an excess of hospital admissions in winter for those living in highly socioeconomically deprived areas and for those living in certain types of housing such as prewar bungalow housing and villas, even after controlling for confounders such as income, age and ethnicity. ${ }^{11}$

Low temperatures may also adversely affect social functioning within the home, with a cold house identified as contributing to depression, limiting mobility and the usable space within the home and contributing to social isolation. ${ }^{29}$ A New Zealand study, in which social housing was upgraded to address issues of general maintenance, overcrowding, and lack of insulation and heating, found that participants reported spending more quality time together in the home and being more confident and relaxed with visitors. Some families also reported positive changes in the area of their children's education and play, and increased enthusiasm for attending school. ${ }^{30}$

A large number of households in New Zealand (approximately $28 \%$ ) use unflued liquefied petroleum gas heaters, although these may not always be the only form of heating. Apart from particulates and other combustion products, these heaters release approximately $1.6 \mathrm{~kg}$ of water for every kilogram of liquefied petroleum gas used, which contributes to condensation and the growth of fungi and mould. Unflued gas heaters also cause elevated levels of nitrogen dioxide $\left(\mathrm{NO}_{2}\right)$ in the indoor environment. $^{31}$ More than one meta-analysis has found a significant association between $\mathrm{NO}_{2}$ levels and exacerbation of bronchial hyper-responsiveness and asthma symptoms. ${ }^{32} 33$

\section{EDUCATION AND SCHOOL ABSENCE IN NEW ZEALAND}

New Zealand's education system compares favourably with other countries in the Organisation for Economic Co-operation and Development. The 2006 Programme for International Student Assessment Report, which surveyed the academic performance of 15-year olds from 57 countries, found that compared to New Zealand, only two other countries performed significantly better in scientific competencies, only three in reading literacy and only five in mathematical literacy. ${ }^{34}$

Nevertheless, school absenteeism is increasing in New Zealand, as shown by the nationwide school attendance survey, which was carried out by the Ministry of Education the week of 21-25 August $2006 .{ }^{35}$ The overall absence rate for all students was $11.5 \%$ of student-days in 2006 , compared to $10.9 \%$ in 2004 and $8.7 \%$ in $2002 .{ }^{36}$ The rise in absences has largely been the result of an increase in truancy rates, which rose from an average of $2.7 \%$ in 2002 to $3.4 \%$ in 2004 and $4.1 \%$ in $2006 .^{35}$

New Zealand schools are each assigned a decile ranking (a measure of the socioeconomic status of the community from which the student population is drawn), with decile 1 being the lowest and decile 10 the highest. Absence increases as decile ranking decreases, with an average absence rate of $13.1 \%$ of student-days for decile 1 schools compared with $8.9 \%$ for decile 10 schools. This was largely due to the difference in truancy 
rates, which were $6.3 \%$ of student-days for decile 1 schools compared with $1.8 \%$ for decile 10 schools. ${ }^{35}$

Absence tends to increase as the average age of students increases. This is in large part due to the sharp rise in truancy from about age 12 . There are also variations in absence rates by ethnicity and sex. Girls had slightly higher rates of both explained absences and truancy at all ages, a finding that is well supported by other international studies. ${ }^{37-39}$

Although most schools do not employ a dedicated school nurse, teaching staff are aware of which students have asthma. Students with doctor-diagnosed asthma will normally have a management plan for their asthma, which will include the use of inhalers as required. Societies such as Asthma NZ run educational programmes for staff and students and supply emergency medication packs to schools.

\section{STUDY METHODS}

The full methods of this study, with an outline of the health effects found, have been published elsewhere. ${ }^{40}$ Briefly, the study was carried out in five communities: Porirua, the Hutt Valley, Christchurch, Dunedin and Bluff. The inclusion criteria were a household where there was a child aged between 6 and 12 years, with doctor-diagnosed asthma, who had asthma symptoms and had used asthma medication in the previous 12 months. Further inclusion criteria were that the main form of household heating had to be a plug-in electric heater, open fire or unflued gas heater; the child had to be sleeping in the house at least four nights of the week, and the family had to intend to remain in the same home until November 2006. Households were recruited mainly though primary healthcare organisations that worked in the asthma field, although some were also recruited from advertisements in local newspapers and radio.

The heater installations for the intervention group were carried out in the autumn of 2006, before winter. The control group had their heaters installed from October 2006, once all the study data had been collected. Households were allowed to choose their preferred new heater option (heat pump, wood pellet burner or flued gas heater). Each household was randomised individually to the intervention or control group by an independent statistician, with two stratification limitations; that the number of households in both groups was the same by both region and preferred new heater type. This was done for practical considerations to ensure that each regional contractor installing the heaters had a similar ratio of heaters to install before and after the intervention. This also helped us control for the effects of children being in different cities, although regional variations in climate in New Zealand are generally small.

Each child's school was contacted by telephone and followed up by email or letter. Permission forms, previously signed by the child and parent, were either posted or faxed if requested. In all cases, a customised form for the absence data was sent, headed with the school name and containing the relevant children's names. Term-by-term absence data going back to 2004 were initially requested to have detailed information about previous absence patterns. However, after feedback from schools as the study progressed, we asked for only a term-by term breakdown of absence data for 2006, with some extra historical data if possible. This absence information for 2006 was critical because it allowed us to separate out the term 1 summer absence patterns (when the heaters had either not been installed or were unlikely to be in use) from the terms 2 and 3 winter absence patterns (after the installation, when the heaters were likely to have an effect). A child was only considered to have complete absence data if we had this term-by-term breakdown for 2006

The information provided by schools generally only specified days absent, without giving a reason. In a very few cases, where the school indicated a reason for an exceptionally long absence not due to illness, the absence data were adjusted accordingly. Absence data were entered into an Excel spreadsheet as received and the form from the school filed alphabetically in a secure location. Data were analysed using generalised linear models, which included the most important confounders and the quasiPoisson link function. Poisson models have been used in previous studies of school absenteeism. ${ }^{38}$ The appropriateness of the models was assessed by examination of the null and residual deviances and the dispersion factor. The statistical programme $\mathrm{R}$ V.2.4.1 (www.r-project.org) was used for all analyses.

\section{RESULTS}

The heating intervention resulted in significant improvements in objective measurements of temperature and indoor pollutants. After the intervention, the average living room temperature of the intervention households was $17.07^{\circ} \mathrm{C}$ compared with $15.97^{\circ} \mathrm{C}$ for the control group households, a difference of $1.10^{\circ} \mathrm{C}$ $(p<0.001)$. Similarly, the average bedroom temperature of the intervention households was $14.84^{\circ} \mathrm{C}$ compared with $14.26^{\circ} \mathrm{C}$ for the control group households, a difference of $0.57^{\circ} \mathrm{C}$ $(p<0.03)$. The geometric mean $\mathrm{NO}_{2}$ levels in the living rooms of intervention households was $8.5 \mu \mathrm{g} / \mathrm{m}^{3}$ compared with $15.75 \mu \mathrm{g} / \mathrm{m}^{3}$ in the control households $(\mathrm{p}<0.001)$. Similarly, the geometric mean $\mathrm{NO}_{2}$ levels in the bedrooms of intervention households was $7.3 \mu \mathrm{g} / \mathrm{m}^{3}$ compared with $10.9 \mu \mathrm{g} / \mathrm{m}^{3}$ in the control households $(\mathrm{p}<0.001)$.

Figure 2 shows the flow diagram for the study. As shown, 349 (85\%) of 409 households successfully completed the study. There was some further loss to follow-up in obtaining school absence data, with complete absence data obtained for children in $269(66 \%)$ households.

Table 1 compares the children who have complete absence data to children who have incomplete (or no) data. The differences in the two groups were tested by using a two-sample test for equality of proportions with continuity correction. There were no statistically significant differences at baseline in age, sex, the type of school attended, the use of gas appliances or smoking inside the home between these two groups. However, significant regional differences reflect the fact that much of the data for Hutt Valley schools was collected before the importance of having term-by-term data was fully realised. In addition, personal visits to facilitate data collection were made to schools in Lower Hutt, Porirua and Christchurch; however, for financial reasons, this was not possible for schools in Dunedin and Bluff. A significant variation in the amount of complete data collected for Māori and Pacific island children may be related to regional variations or to the fact that Māori children tend to have more frequent changes of residence. ${ }^{41}$

Table 2 looks at the differences in possible confounders for children with complete data in the intervention group versus the control group. There are no significant differences in any variable except household income, where it appears that households in the control group were more likely $(p=0.04)$ to be have a low income and less likely to have a medium income $(p=0.04)$. There was no difference in the numbers of high income or unknown income. We have controlled for income in our analysis.

Figure 3 shows the number of days absent in terms 2 and 3 (100 school days) for children in the intervention and control 
Figure 2 Study flow diagram.

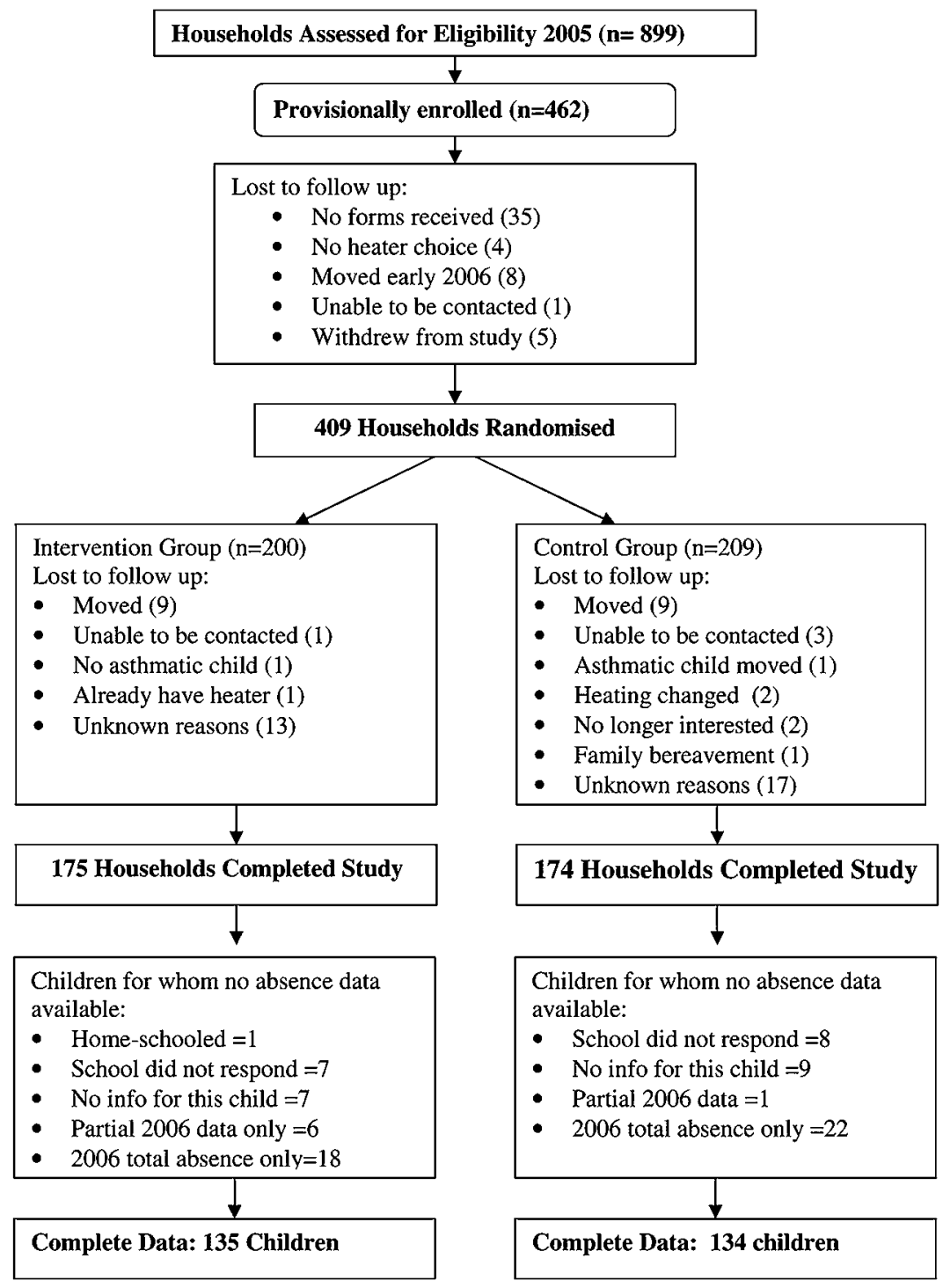

groups after the intervention. In the control group, the average absence was 9.6 days. The median absence was 7.5 days, with a maximum absence of 62 days, minimum of zero days, and upper and lower quartiles of 14.0 and 3.0 days, respectively. In comparison, in the intervention group, the average days absent was 7.6 days. The median absence was 7.0 days, with a maximum absence of 42 days, minimum of zero days, and upper and lower quartiles of 10.5 and 2.75 days, respectively.

Table 3 shows the results from an analysis of covariance (ANCOVA). Children in the intervention group had a statistically significant reduction in the number of days absent (effect ratio 0.79 , confidence interval (CI) 0.66 to 0.96 ). Children of Pacific Island ethnicity (effect ratio 1.24 , CI 1.00 to 1.55 ), children from low-income households (effect ratio 1.39, CI 1.12 to 1.72) and children from households were there was smoking inside (effect ratio 1.29, CI 1.04 to 1.59 ) had significantly more days off school. There was no significant difference for children of Māori ethnicity, or by sex, parental history of asthma, or type of school.

The analysis was repeated for a substantial subset of children $(57 \%)$ living in households where the previous main form of heating had been a portable unflued gas heater. In this subset, children in the intervention group had a significant reduction (effect ratio 0.72 , CI 0.55 to 0.93 ) in days absent compared to the control group.

In addition to absence data for the children with asthma, complete absence data were also collected for 194 siblings, 54\% of whom did not have asthma. The average winter absence for siblings in the intervention group was 6.7 days compared with 7.4 days for siblings in the control group, an improvement of 1.3 days. Table 4 shows the ANCOVA using the same factors as above, plus controlling for the presence of asthma. Although we found reduced school absence for siblings in the intervention group, the result did not quite reach statistical significance $(p=0.09)$. We did not include siblings in the main study results to avoid household clustering effects.

\section{DISCUSSION}

The results reported on in this paper show that more effective heating in homes, previously reliant on unflued gas heating, open fires or low-kilowatt electric heaters, can reduce winter school absence for asthmatic children by an average of $21 \%$, or approximately 1.9 days over the middle two (winter) school terms. This represents a large amount of potentially preventable school absence, when taken over the entire New Zealand population of asthmatic children living in households currently 
Table 1 Children with complete versus incomplete data

\begin{tabular}{|c|c|c|c|c|c|}
\hline \multirow[b]{2}{*}{ Sex (male) } & \multicolumn{2}{|c|}{$\begin{array}{l}\text { Complete data } \\
(n=269)\end{array}$} & \multicolumn{2}{|c|}{$\begin{array}{l}\text { Incomplete } \\
(\text { or no) data } \\
(n=80)\end{array}$} & \multirow{2}{*}{$\begin{array}{c}\begin{array}{c}\text { Significance } \\
\text { of difference }\end{array} \\
0.62\end{array}$} \\
\hline & $59 \%$ & 160 & $53 \%$ & 42 & \\
\hline Parental asthma & $56 \%$ & 151 & $45 \%$ & 36 & 0.10 \\
\hline \multicolumn{6}{|l|}{ Ethnicity } \\
\hline Māori & $32 \%$ & 87 & $49 \%$ & 39 & 0.01 \\
\hline Pacific Island & $22 \%$ & 58 & $9 \%$ & 7 & 0.01 \\
\hline NZ European & $67 \%$ & 180 & $58 \%$ & 47 & 0.22 \\
\hline Other & $9.3 \%$ & 25 & $59 \%$ & 5 & 0.53 \\
\hline \multicolumn{6}{|l|}{ Region } \\
\hline Porirua & $27 \%$ & 72 & $8 \%$ & 6 & 0.0005 \\
\hline Hutt Valley & $24 \%$ & 65 & $56 \%$ & 45 & $<0.0001$ \\
\hline Christchurch & $33 \%$ & 89 & $5 \%$ & 4 & $<0.0001$ \\
\hline Dunedin/Bluff & $16 \%$ & 43 & $31 \%$ & 25 & 0.004 \\
\hline \multicolumn{6}{|l|}{ School } \\
\hline Contributing & $32 \%$ & 85 & $35 \%$ & 28 & 0.66 \\
\hline Full primary & $32 \%$ & 87 & $43 \%$ & 34 & 0.12 \\
\hline Intermediate & $20 \%$ & 53 & $14 \%$ & 11 & 0.30 \\
\hline Secondary & $16 \%$ & 44 & $9 \%$ & 7 & 0.13 \\
\hline \multicolumn{6}{|l|}{ Income } \\
\hline$<\$ 38000$ & $38 \%$ & 102 & $39 \%$ & 31 & 0.98 \\
\hline $\begin{array}{l}\$ 38000- \\
\$ 60000\end{array}$ & $27 \%$ & 72 & $19 \%$ & 15 & 0.19 \\
\hline$>\$ 60000$ & $17 \%$ & 46 & $25 \%$ & 20 & 0.16 \\
\hline Not specified & $18 \%$ & 49 & $18 \%$ & 14 & 0.98 \\
\hline Smoking inside & $21 \%$ & 57 & $21 \%$ & 17 & 0.89 \\
\hline
\end{tabular}

using these forms of heating. Data from the 2006 NZ Census showed that there were approximately 592000 children aged 5-14 years. Of these children, approximately one in four, or 148000 children, will experience symptoms of asthma.

Data from the 2006 Census also showed that around $30 \%$ of New Zealand households are using either unflued heaters or no

Table 2 Children with complete data-intervention versus control group

\begin{tabular}{|c|c|c|c|c|c|}
\hline \multirow[b]{2}{*}{ Sex (male) } & \multicolumn{2}{|c|}{$\begin{array}{l}\text { Intervention } \\
\text { group } \\
(\mathrm{n}=135)\end{array}$} & \multicolumn{2}{|c|}{$\begin{array}{l}\text { Control } \\
\text { group } \\
(n=134)\end{array}$} & \multirow{2}{*}{$\begin{array}{l}\begin{array}{l}\text { Significance } \\
\text { of difference }\end{array} \\
0.23\end{array}$} \\
\hline & $56 \%$ & 75 & $63 \%$ & 85 & \\
\hline Parental asthma & $56 \%$ & 75 & $57 \%$ & 76 & 0.95 \\
\hline \multicolumn{6}{|l|}{ Ethnicity } \\
\hline Māori & $31 \%$ & 42 & $34 \%$ & 45 & 0.60 \\
\hline Pacific Island & $24 \%$ & 33 & $19 \%$ & 25 & 0.31 \\
\hline NZ European & $64 \%$ & 86 & $70 \%$ & 94 & 0.32 \\
\hline Other & $11 \%$ & 15 & $7.5 \%$ & 10 & 0.41 \\
\hline \multicolumn{6}{|l|}{ Region } \\
\hline Porirua & $25 \%$ & 34 & $28 \%$ & 38 & 0.65 \\
\hline Hutt Valley & $28 \%$ & 38 & $20 \%$ & 27 & 0.16 \\
\hline Christchurch & $33 \%$ & 45 & $33 \%$ & 44 & 0.97 \\
\hline Dunedin/Bluff & $13 \%$ & 18 & $19 \%$ & 25 & 0.31 \\
\hline \multicolumn{6}{|l|}{ School } \\
\hline Contributing & $34 \%$ & 46 & $29 \%$ & 39 & 0.46 \\
\hline Full primary & $32 \%$ & 43 & $33 \%$ & 44 & 0.97 \\
\hline Intermediate & $20 \%$ & 27 & $19 \%$ & 26 & 0.98 \\
\hline Secondary & $14 \%$ & 19 & $19 \%$ & 25 & 0.39 \\
\hline \multicolumn{6}{|l|}{ Income } \\
\hline$<\$ 38000$ & $44 \%$ & 60 & $31 \%$ & 42 & 0.04 \\
\hline $\begin{array}{l}\$ 38000- \\
\$ 60000\end{array}$ & $21 \%$ & 28 & $33 \%$ & 44 & 0.04 \\
\hline$>\$ 60000$ & $16 \%$ & 22 & $18 \%$ & 24 & 0.48 \\
\hline Not specified & $19 \%$ & 25 & $18 \%$ & 24 & 0.98 \\
\hline Smoking inside & $21 \%$ & 28 & $22 \%$ & 29 & 0.97 \\
\hline
\end{tabular}

Days Absent from school during winter 2006

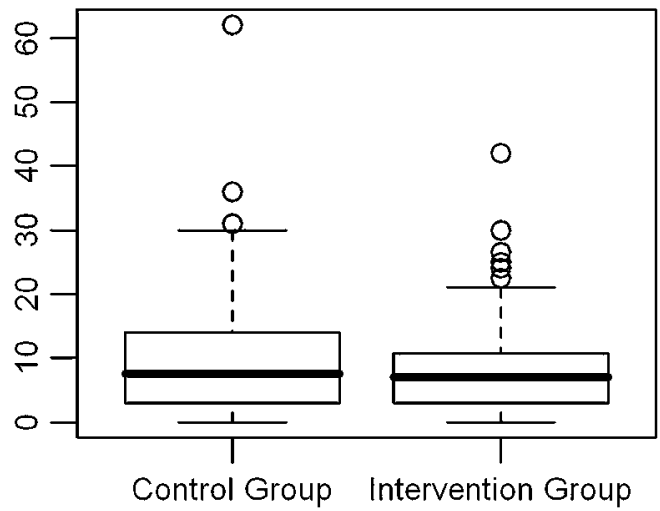

Figure 3 Days absent from school during winter 2006.

heating. Assuming that the 148000 asthmatic children referred to are proportionately distributed in these households would mean that up to 44400 children are living with suboptimal heating. Using an average figure of 1.9 days of potentially preventable absence for each asthmatic child gives a total of approximately 84000 potentially preventable days of school absence each winter.

These figures almost certainly under-represent the true situation, as the effect on siblings has not been accounted for nor have the figures included those living in households using inadequate electric heating. The analysis also ignores the days lost for the approximately 300000 children aged 15-19, some of whom would still be at school. Even more importantly however, this simple analysis overlooks the income, housing and other social disparities that exist, as low-income households, who struggle most to afford power, are also likely to be the ones with the most children. Lower-income households are also less likely to provide private study spaces and material resources such as computers and study materials to support a child's learning, ${ }^{42} 43$ and the adults in these houses are less likely to be well educated themselves. These factors affect the ways in which the disruption to a child's education can be accommodated for.

The assertion is often made that absenteeism is associated with poorer educational outcomes and social adjustment. The situation is complex, as some studies have shown that a low

Table 3 Multivariate ANCOVA model for the effect on school absence of specified factors

\begin{tabular}{llll}
\hline Contributing factor & Effect ratio* & CI & p Value \\
\hline Intervention group & 0.79 & 0.66 to 0.96 & 0.02 \\
Parental asthma & 0.89 & 0.73 to 1.08 & 0.25 \\
Sex (male) & 0.98 & 0.80 to 1.19 & 0.82 \\
Māori ethnicity & 1.05 & 0.85 to 1.29 & 0.66 \\
Pacific Island ethnicity & 1.24 & 1.00 to 1.55 & 0.05 \\
Full primary school & 1.19 & 0.93 to 1.51 & 0.16 \\
Intermediate school & 1.11 & 0.84 to 1.45 & 0.46 \\
Secondary school & 1.10 & 0.82 to 1.47 & 0.53 \\
Low income (<\$38 000) & 1.39 & 1.12 to 1.72 & 0.003 \\
Smoking inside & 1.29 & 1.04 to 1.59 & 0.02 \\
\hline $\begin{array}{l}\text { ANCOVA, analysis of covariance. } \\
\text { Ethnicity was referenced against New Zealand European or Other. The level of schooling }\end{array}$ \\
was referenced against contributing schools (5-10 years). Parental asthma was \\
considered to exist if either parent had ever been diagnosed with asthma. Smoking inside \\
was considered to exist if any level of smoking inside was reported. \\
*The effect ratio is the average number of days absent for those having the specified factor \\
divided by the average number of days absent for those not having the factor after \\
controlling for all other specified factors. Null deviance: 3107.7 on 251 df. Residual \\
deviance: 2123.9 on 240 df. Dispersion factor=9.617085.
\end{tabular}


Table 4 Multivariate ANCOVA model for siblings

\begin{tabular}{llll}
\hline Contributing factor & Effect ratio* & CI & p Value \\
\hline Intervention group & 0.82 & 0.65 to 1.03 & 0.02 \\
Asthma & 1.04 & 0.82 to 1.31 & 0.74 \\
Parental asthma & 0.89 & 0.73 to 1.08 & 0.25 \\
Sex (male) & 0.84 & 0.66 to 1.07 & 0.16 \\
Māori ethnicity & 1.21 & 0.94 to 1.57 & 0.14 \\
Pacific Island ethnicity & 1.24 & 1.00 to 1.55 & 0.76 \\
Full primary school & 1.05 & 0.78 to 1.41 & 0.88 \\
Intermediate school & 1.21 & 0.84 to 1.74 & 0.31 \\
Secondary school & 1.35 & 0.95 to 1.93 & 0.10 \\
Low income (<\$38 000) & 1.08 & 0.82 to 1.42 & 0.60 \\
Smoking inside & 1.49 & 1.13 to 1.96 & 0.006 \\
\hline
\end{tabular}

ANCOVA, analysis of covariance.

We have controlled for asthma, since $54 \%$ of siblings did not have asthma. Ethnicity was referenced against New Zealand European or other. The level of schooling was referenced against contributing schools (5-10 years). Parental asthma was considered to exist if either parent had ever been diagnosed with asthma. Smoking inside was considered to exist if any level of smoking inside was reported.

*The effect ratio is the average number of days absent for those having the specified factor divided by the average number of days absent for those not having the factor after controlling for all other specified factors. Null deviance: 1881.7 on $172 \mathrm{df}$. Residual deviance: 1241.7 on $160 \mathrm{df}$. Dispersion factor $=7.542391$.

level of absenteeism does not cause any adverse effect on academic outcomes. ${ }^{3}$ However, there is evidence that higher rates of absenteeism can have an adverse impact on achievement. New Zealand research on the participants of the Competent Learners study as they turned 16 revealed some interesting results. Students with good or very good attendance scored as well as students with excellent attendance in terms of the number of New Zealand Certificate of Educational Attainment Level 1 credits gained. In contrast, only $36 \%$ of students with fair attendance gained a comparable number of credits, and this dropped to $1 \%$ of students in the group with poor attendance. ${ }^{44}$ These New Zealand results confirm findings from a recent US study where absenteeism was found to have a significant $(p<0.001)$ inverse relationship with standardised test scores. ${ }^{45}$

Literature from both New Zealand and elsewhere demonstrates that attendance and achievement are interlinked, with low achievement itself a risk for poor attendance. ${ }^{44}$ Unless the home environment is very supportive, or there are excellent school-based systems in place to ensure students can catch up on work missed during absences, there is a real risk that frequent absences can start a process of disengagement with schooling that is difficult to arrest.

Apart from the obvious effects on academic outcomes, disengagement from school has also been found to be a risk factor for poor mental health, ${ }^{46}$ smoking, antisocial behaviour, and drug related offences ${ }^{47}$ and for early sexual initiation (before the age of 16) for both boys and girls in New Zealand. ${ }^{48}$

\section{STUDY LIMITATIONS}

Although this study had a robust experimental design, there were limitations in data collection. Compared to the population as a whole, our study had more low-income households and more Māori and Pacific Island households. Our study sample was geographically clustered, albeit in several different regions. Region was initially controlled for in the ANCOVA but was found to have no effect.

The absence data collected were also biased towards proportionately more complete data available from the Porirua and Christchurch regions. For children with complete data, more came from the lowest-income households in the intervention group than in the control group. The last factor was accounted for by controlling for income in the analysis.
A second limitation is that, although the effect of the intervention in reducing school absence for asthmatic children is clear, the mechanism by which this happens is not. We hypothesised that this effect is due to increased temperature and reduced indoor air pollution leading to reduced asthma symptoms, possibly through reduced illness; however, as outlined in figure 1, many possible alternative mechanisms exist. It is possible that any child who awakens in a cold home is more likely to stay in bed longer and miss school. Alternatively, a warmer house may lead to better family functioning and routines, and hence more support for the child's education. The fact that the asthmatic children's siblings (54\% were non-asthmatic) also had an improvement in school absence suggests that whatever the mechanism are, at least some of them affect both asthmatic and non-asthmatic children. It is indeed possible that the greater benefit seen by the asthmatic children is due to their higher total number of days off and hence greater room for improvement.

Although this study has an important strength in terms of the quantity and quality of absence data collected, especially when compared to many other studies reporting on school absence as an outcome, ${ }^{3}$ it is a limitation that the reasons for absences were unknown. The validity of these data, in showing an effect because of the replacement heating, relies on the proportion of days absent for reasons unrelated to illness or housing conditions being similar in both the intervention and non-intervention groups. This necessitated the collection of a large quantity of data to allow the underlying trends to emerge.

\section{CONCLUSION}

Our study considerably strengthens the evidence that installing effective non-polluting home heating reduces school absences for children with asthma. This is an important finding given the significance of asthma as a contributing factor in school absence. The robustness of these conclusions was strengthened by the collection of a previous absence history for each child and the use of a control group. We also used independently verified data from school statutory records rather than relying on parentreported data.

\section{What is already known on this subject}

Cold, damp homes increase respiratory illnesses, especially in children with asthma.

- Children with chronic illnesses, such as asthma, have more days off school.

- It was not known whether improving home heating reduced school absences.

\section{What does this study add}

Installing more effective heating in the homes of children with asthma raises the indoor temperature and lowers the indoor air pollution.

- Installing more effective home heating reduces symptoms in children with asthma.

- Children with asthma, living in warmer homes, have significantly fewer days off school due to their asthma. 


\section{Policy implications}

Installing effective heating in the homes of children with asthma is an important way of reducing their asthma symptoms and maintaining their school attendance.

Author footnote: * Housing, Heating and Health Study Team P Howden-Chapman, N Pierse, S Nicholls, J Bennett, H Viggers, C Cunningham, R Phipps, M Boulic, P Fjällström, R Chapman, S Free, D Shields, B Lloyd, K Wickens, C Cunningham, A Woodward, M Baker, C Bullen, J Crane. S Nicholls, He Kainga Oranga/Housing and Health Research Programme, University of Otago, Wellington, P0 7343, Wellington South, New Zealand. J Gillespie-Bennett, He Kainga Oranga/Housing and Health Research Programme, University of Otago, Wellington, PO 7343, Wellington South, New Zealand. M Cunningham, BRANZ Ltd, Moonshine Rd, Porirua City, New Zealand. R Phipps, School of Engineering and Advanced Technology, Massey University, Private Bag 11 222, Palmerston North, New Zealand. M Boulic, School of Engineering and Advanced Technology, Massey University, Private Bag 11 222, Palmerston North, New Zealand. P Fjällström, School of Engineering and Advanced Technology, Massey University, Private Bag 11 222, Palmerston North, New Zealand. R Chapman, School of Geography, Environment and Earth Sciences, Victoria University of Wellington, New Zealand. B Lloyd, Energy Studies, Physics Department, University of Otago, Dunedin, New Zealand. K Wickens, Wellington Asthma Research Group, University of Otago, Wellington, PO 7343, Wellington South, New Zealand. D Shields, He Kainga Oranga/Housing and Health Research Programme, University of Otago, Wellington, PO 7343, Wellington South, New Zealand. M Baker, He Kainga Oranga/Housing and Health Research Programme, University of Otago, Wellington, PO 7343, Wellington South, New Zealand. C Cunningham, Research Centre for Māori Health \& Development, Massey University, Wellington, New Zealand. A Woodward, School of Population Health, University of Auckland, New Zealand. C Bullen, School of Population Health, University of Auckland, New Zealand. J. Crane, He Kainga Oranga/Housing and Health Research Programme, University of Otago, Wellington, PO 7343, Wellington South, New Zealand.

Acknowledgements We are grateful to the many school teachers and administrators who assisted us with providing data for this study. Thanks also to the funders of the Housing, Heating and Health Study: the Health Research Council of New Zealand, Contact Energy, Ministry for the Environment, the Energy Efficiency and Conservation Authority, Hutt Valley District Health Board, Capital Coast District Health Board and the LPG Association.

Funding Health Research Council of New Zealand, Auckland; Contact Energy Limited, The Terrace, Wellington; Ministry for the Environment, Wellington; Energy Efficiency and Conservation Authority, Wellington; Hutt Valley District Health Board, High Street, Lower Hutt; Capital and Coast District Health Board, Wellington South; LPG Association of New Zealand, Wellington.

\section{Competing interests None.}

Ethics approval This study was conducted with the approval of the Multi-Region Ethics Committee (NZ).

Contributors SF: data collection from schools, processing of data, preparation of tables and diagrams, main authorship of paper; PHC: head of the study team, overview of study including background, contributing author; NP: biostatistician, overview of data collection procedure, statistical methods, analysis and interpretation of data; HV: assistance with data processing, diagrams, critiquing and contributing to article; Housing and Health Study Team: various roles to ensure the intervention took place as planned, critiquing and proof reading final versions of article.

Provenance and peer review Not commissioned; externally peer reviewed.

\section{REFERENCES}

1. Graham H. Unequal lives: health and socioeconomic inequalities. Maidenhead: Berkshire: Open University Press, 2007

2. Ministry of Health. Reducing inequalities in health. Wellington: Ministry of Health, 2002.

3. Taras H, Potts-Datema W. Childhood asthma and student performance at school. J Sch Health 2005;75:296.

4. Wang LY, Zhong Y, Wheeler L. Direct and indirect costs of asthma in school -age children. Prev Chronic Dis 2005;75;8:296-312 serial online. http://www.cdc.gov/ pcd/issues/2005/jan/04 0053.htm (accessed 28 Feb 2010)

5. Moonie SA, Sterling $\overline{D A}$, Figgs $L$, et al. Asthma status and severity affects missed school days. J Sch Health 2006;76:18-24.

6. Millard MW, Johnson PT, Hilton A, et al. Children with asthma miss more school -fact or fiction. Chest 2009;135:303-6.
7. Clark NM, Brown R, Joseph CLM, et al. Effects of a comprehensive school-based asthma program on symptoms, parent management, grades and absenteeism. Chest 2004;125:1674-9.

8. Wood PR, Hidalgo HA, Prihoda TJ, et al. Hispanic children with asthma: morbidity. Pediatrics 1993;91:62-9.

9. Bauman L, Wright E, Leickly FE, et al. Relationship of adherence to pediatric asthma morbidity among inner-city children. Pediatrics 2002;110:e1-7.

10. Gartland HJ, Day HD. Family predictors of the incidence of children's asthma symptoms: expressed emotion, medication, parent contact, and life events. J Clin Psychol 1999;55:573-84.

11. The role of housing age and socio-economic status in New Zealand excess winter hospitalisation patterns. 5th Housing and Health Conference; 2007; University of Warwick, Coventry.

12. Baker M, Keall M, Au EL, et al. Home is where the heart is-most of the time. N Z Med J 2007;120:U2769.

13. Richardson G, Eick S, Jones R. How is the indoor environment related to asthma? literature review. J Adv Nurs 2005;52:328-39.

14. Arlian LG. Water balance and humidity requirements of house dust mites. Exp App/ Acarol 1992;16:15-35.

15. Dharmage S, Bailey $\mathrm{M}$, Raven J, et al. Mouldy houses influence symptoms of asthma among atopic individuals. Clin Exp Allergy 2002;32:714-20.

16. Strachan DP. The role of environmental factors in asthma. Br Med Bull 2000:56:865-82

17. Burr ML, Matthews IP, Arthur RA, et al. Effects on patients with asthma of eradicating visible indoor mould: a randomised controlled trial. Thorax 2007; 62:767-72

18. Kercsmar CM, Dearborn DG, Schlucter M, et al. Reduction in asthma morbidity in children as a result of home remediation aimed at moisture sources. Environ Health Perspect 2006;114:1574-80.

19. Krieger JW, Takaro TK, Song L, et al. The Seattle-King County Healthy Homes Project: a randomized, controlled trial of a community health worker intervention to decrease exposure to indoor asthma triggers. Am J Public Health 2005;95:652-9.

20. NAS. Clearing the air: asthma and indoor air exposures. Washington, DC: National Academy of Sciences Institute of Medicine, 2000.

21. Sporik R, Chapman MD, Platts-Mill TAE. House dust mite exposure as a cause of asthma. Clin Exp Allergy 1992;22:897-906.

22. Somerville M, Mackenzie I, Owen P, et al. Housing and health: does installing heating in their homes improve the health of children with asthma? Public Health 2000:114:434-9.

23. Diette GB, Markson L, Skinner EA, et al. Nocturnal asthma in children affects school attendance, school performance, and parents' work attendance. Arch Pediatr Adolesc Med 2000;154:923.

24. Howden-Chapman P, Matheson A, Viggers $\mathrm{H}$, et al. Retrofitting houses with insulation to reduce health inequalities: results of a clustered, randomised trial in a community setting. Br Med J 2007;334:460-4.

25. Energy Use in New Zealand Households-Year 7 HEEP Report. Porirua: Building Research institute of New Zealand (BRANZ), 2003.

26. Howden-Chapman P, Viggers $H$, Chapman $R$, et al. Warm homes: drivers of the demand for heating in the residential sector in New Zealand. Energy Policy 37:9:3387-99.

27. Davie GS, Baker MG, Hales $S$, et al. Trends and determinants of excess winter mortality in New Zealand: 1980 to 2000. BMC Public Health 2007;7:263

28. Telfar-Barnard L, Baker M, Hales $S$, et al. The role of housing type and socioeconomic status in New Zealand excess winter hospitalisation patterns In: Ormandy D, ed. Fifth Warwick Healthy Housing Conference. Warwick, United Kingdom: University of Warwick, 2008.

29. Harrington BE, Heyman B, Merleau-Ponty N, et al. Keeping warm and staying well: findings from the qualitative arm of the Warm Homes Project. Health Soc Care Community 2005;13:259-67.

30. Clinton J, Mahoney F, Irvine R, et al. The Healthy Housing Programme: Report of the Outcomes Evaluation (Year Two). Wellington: Housing New Zealand Corporation, 2006.

31. Pilotto LS, Nitschke M, Smith BJ, et al. Randomized controlled trial of unflued gas heater replacement on respiratory health of asthmatic schoolchildren. Int J Epidemiol 2004;33:208-14.

32. Folinsbee LJ. Does nitrogen dioxide exposure increase airways responsiveness? Toxicol Ind Health 1992;8:273-83.

33. Hasselblad VV. Synthesis of environmental evidence: nitrogen dioxide epidemiology studies. Air Waste 1992:42:662-71.

34. Telford M, Caygill R. PISA 2006: how ready are our 15-year-olds for tomorrow's world? Wellington: Ministry of Education, 2007

35. $\mathbf{~ N g ~ L . ~ A t t e n d a n c e , ~ a b s e n c e ~ a n d ~ t r u a n c y ~ i n ~ N e w ~ Z e a l a n d ~ s c h o o l s ~ i n ~ 2 0 0 6 . ~ W e l l i n g t o n : ~}$ Research Division, Ministry of Education, 2007.

36. Attendance absence and truancy in New Zealand schools in 2004. Wellington: Research Division, Ministry of Education, 2005.

37. Malcolm H, Thorpe G, Lowden K. Understanding truancy: links between attendance, truancy and performance. The Scottish Council for Research in Education 1996:1-57.

38. Gilliland FD, Berhane K, Rappaport EB, et al. The effects of ambient air pollution on school absenteeism due to respiratory illnesses. Epidemiology 2001;12:43-54.

39. Reid K. The causes view and traits of school absenteeism and truancy: an analytical review. Research in Education 2005;74:59-82. 
40. Howden-Chapman P, Pierse N, Nicholls S, et al. The effects of improved home heating on childhood asthma: randomised community study. Br Med $\mathrm{J}$ 2008;337:852-55

41. Biddulph F, Biddulph J, Biddulph C. Best evidence synthesis: the complexity of community and family influences on children's achievement in New Zealand. Wellington: Research Division, Ministry of Education, 2003.

42. Caygill R, Chamberlain M. Progress in International Reading Literacy Study: New Zealand's Year 5 Student Achievement 2001. Wellington: Comparative Education Research Unit, 2004.

43. Hawk K, Hill J, Foliaki L, et al. Towards making achievement cool: achievement in multi cultural high schools (AIMHI). Albany: Educational Research and Development Centre, Massey University, 1996.
44. Wylie C. Hipkins R. On the edge of adulthood young people's school and out-of-school experiences at 16. Wellington: New Zealand Council for Educational Research, 2007.

45. Moonie S, Sterling DA, Figgs LW, et al. The Relationship between school absence, academic performance, and asthma status. J Sch Health 2008:78:140-8.

46. Fleming TM, Merry SN, Robinson EM, et al. Self-reported suicide attempts and associated risk and protective factors among secondary school students in New Zealand. Aust N Z J Psychiatry 2007:41:213-21.

47. Curtis NM, Harris J, Heiblum N, et al. Antisocial behaviours in New Zealand youth: prevalence, interventions and promising new directions. Aust N Z J Psychiatry 2002;41:213-21.

48. Paul C, Fitzjohn J, Herbison P, et al. The determinants of sexual intercourse before age 16. J Adolesc Health 2000:27:136-47. 